\title{
Paradigm shift in the local treatment of breast cancer: mastectomy to breast conservation surgery
}

\author{
Kowsi Murugappan ${ }^{1,2}$, Apoorva Saboo ${ }^{1}$, Lu Kuo $^{2}$, Owen Ung ${ }^{1,2}$ \\ ${ }^{1}$ Royal Brisbane Breast Surgery Unit, Department of General Surgery, RBWH, Brisbane, Australia; ${ }^{2}$ University of Queensland, Brisbane, Australia \\ Contributions: (I) Conception and design: K Murugappan; (II) Administrative support: K Murugappan; (III) Provision of study materials or patients: \\ K Murugappan; (IV) Collection and assembly of data: A Saboo, L Kuo; (V) Data analysis and interpretation: O Ung; (VI) Manuscript writing: All \\ authors; (VII) Final approval of manuscript: All authors. \\ Correspondence to: Kowsi Murugappan. Royal Brisbane Breast Surgery Unit, Department of General Surgery, RBWH, Brisbane, Australia. \\ Email: k.murugappan@uq.edu.au.
}

\begin{abstract}
There have been fundamental changes in the approach to breast cancer management over the last century but the primary objective of achieving oncological safety remains unchanged. This evolution is highlighted with a summary of the key evidences in support of the oncological safety of breast conserving surgery (BCS) in early breast cancer (EBC) management. We will also discuss the increasingly pivotal role that neoadjuvant chemotherapy (NACT) may play, in the local treatment of EBC and locally advanced breast cancer (LABC) and the long-term surgical and oncological outcomes.
\end{abstract}

Keywords: Mastectomy; breast conservation surgery (BCS); oncological safety; neoadjuvant chemotherapy (NACT)

Submitted May 14, 2018. Accepted for publication Sep 03, 2018.

doi: 10.21037 /gs.2018.09.01

View this article at: http://dx.doi.org/10.21037/gs.2018.09.01

\section{Introduction}

One hundred years ago, during the Halstedian era, women with breast cancer were treated with surgery alone, radical mastectomy and axillary clearance regardless of the stage at presentation (1). From this 'one size fits all' approach, we have progressed to tailored and personalized management, taking into consideration individual patient and tumour factors. The goal of conservation surgery is to resect the minimum amount of breast tissue to attain the best oncological outcome with optimum aesthetic results.

This overview acknowledges the paradigm shift in our pathological understanding of breast cancer as a heterogeneous disease and how that influences treatment planning. Advancements have led to more accurate and early diagnosis using a variety of new radiological technologies, targeted systemic therapy, precise radiotherapy planning and delivery. Cancer surgery combines oncological principles with plastic surgical techniques to improve the aesthetic with oncoplastic breast conserving surgery (OBCS) and mastectomy with immediate breast reconstruction. It is no longer 'one size fits all' approach.

\section{Breast cancer theories and evolution of BCS}

Halsted proposed that breast cancer spread from the breast to the pectoralis muscle then to regional lymph nodes and then finally to distant sites (1). Based on this very plausible theory, clinicians adopted an aggressive surgical approach to achieve local control. In the 1950's, a less aggressive approach of modified mastectomy, sparing the pectoralis muscles, gained widespread acceptance. There was a transition to local conservatism, influenced by the 'Fisher' theory, that proposed breast cancer was more a systemic disease. The implication was that small tumours were manifestations of systemic disease and may have already metastasized (2). However, in the 1990's the Spectrum theory was realised, combining Fisher and Halstedian theories to recognise that Breast cancer was and is a heterogeneous disease that lies in a spectrum (3). Hence, any persistent disease, locally or regionally can lead to metastatic disease, thereby emphasising the 


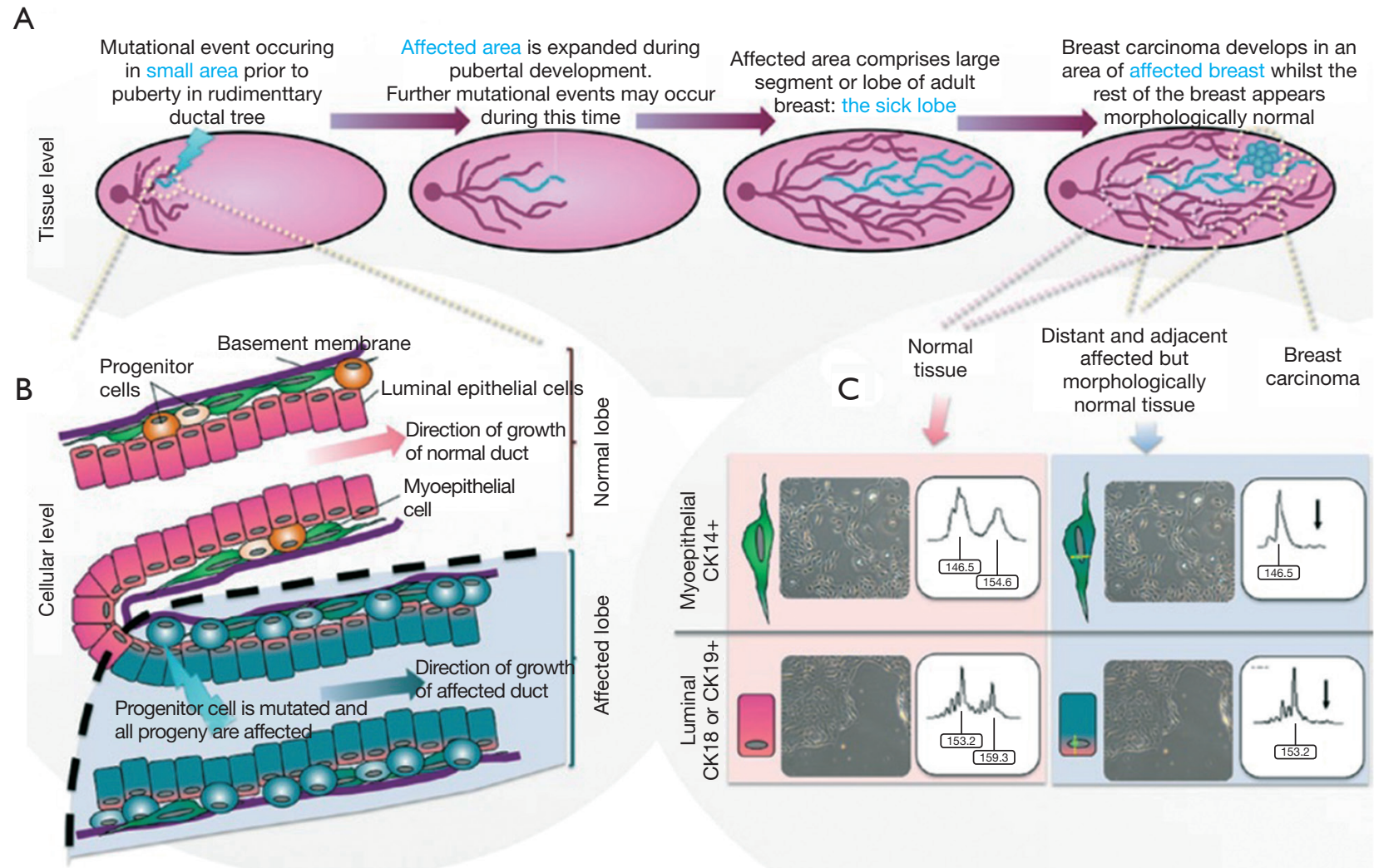

Figure 1 Sick lobe theory (5). (A) Pictorial description of the pathogenesis of genetic alterations leading to breast cancer within a single lobe; (B) cellular level changes from normal to abnormal ductal cells; (C) these genetic alterations proven with immunostaining.

importance of adequate loco-regional control with surgery and radiotherapy. The 'sick lobe' theory of breast cancer suggests that it is a lobar disease appearing as in-situ or invasive tumour in a single lobe at the early stage of the disease. Subsequent mutations in the malignant cells, lead to invasion of adjacent lobes and lymphatic spaces (4) (Figure 1). The significance of this theory for breast conservation surgery is detailed later in this issue.

\section{Oncological safety of BCS versus mastectomy in early breast cancer (EBC)}

The term oncological safety refers to the ability of a given procedure to remove any detectable tumour. Comparisons can be made by measuring a set of time-to-event end points: overall survival (OS), disease free survival (DFS) or recurrence patterns like locoregional recurrence (LRR) or distant recurrence (DR) (6). These endpoints are defined in the guidelines published in 2015 to standardise and assist in comparisons between breast cancer trials (7).
The oncological safety of BCS compared to radical and modified mastectomy is well established. Six key prospective RCTs are summarised in (Table S1). Two of these larger trials-NSABP B-06 and EORTC have published the results of more than 20 years of follow up $(8,9)$. The NSABP B-06 20-year results showed that local recurrence was significantly lower when BCS was combined with radiotherapy and there was no difference in DFS, Distant DFS and OS (8) (Figures 2,3). The Milan study's 20 -year results show that there was a higher incidence of local recurrence in the Breast Conservation Treatment (BCS + radiotherapy) group compared to Halsted's mastectomy group and similar to NSABP B-06, no difference was found in OS, DFS, distant DFS (Table 1). However, use of systemic therapy was limited to only node positive patients, which differs from contemporary practice where we also take into account of molecular subtype in addition to nodal stage. The Milan study preceded routine use of endocrine therapy that contemporaneously would be regarded as an essential component of adjuvant therapy for hormone dependent 


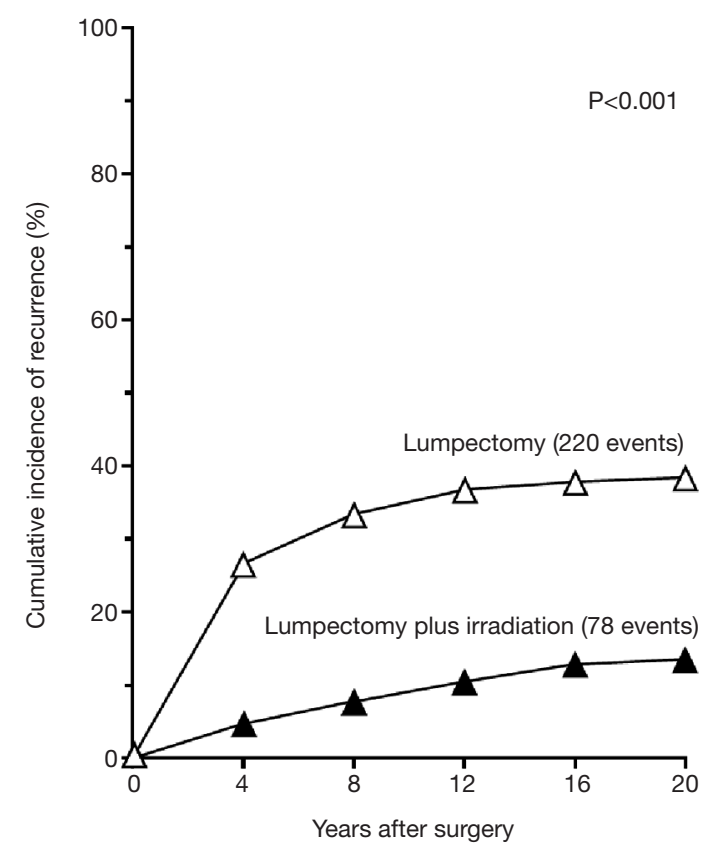

Figure 2 NASABP B-06 20 years follow-up results: cumulative Incidence of a first recurrence of cancer in the Ipsilateral in women treated with lumpectomy alone $(\mathrm{n}=570)$ and lumpectomy + breast radiation $(\mathrm{n}=567)$. The data are for women whose specimens had tumour-free margins (8). breast cancer.

More recent large retrospective and prospective non-randomised studies also favour BCS over mastectomy with respect to survival. Three non-randomised studies that reported on LRR between BCS and mastectomy showed that there was no difference in LRR (11) (Table 2).

These trials have consolidated the evidence for BCT, consisting of excision of tumour with negative margins followed by radiotherapy. The National Institute of Health (NIH) released a consensus statement in 1991 recommending BCT as preferred surgical treatment of most women with EBC surgery (17).

\section{Total mastectomy vs. Iumpectomy}

In order to minimise local recurrence (LR), achieving a negative margin is an important tenet of BCS for invasive breast cancer. In a review of the evidence, the SSO/ ASTRO consensus guideline in 2014 (18) recommends no tumour cells at the margin (definition of negative margin) as adequate to prevent LR, without requirement for a wider excisional margin. A positive margin is associated with a two-fold increased risk of LR, which is independent of tumour subtype or the use of adjuvant
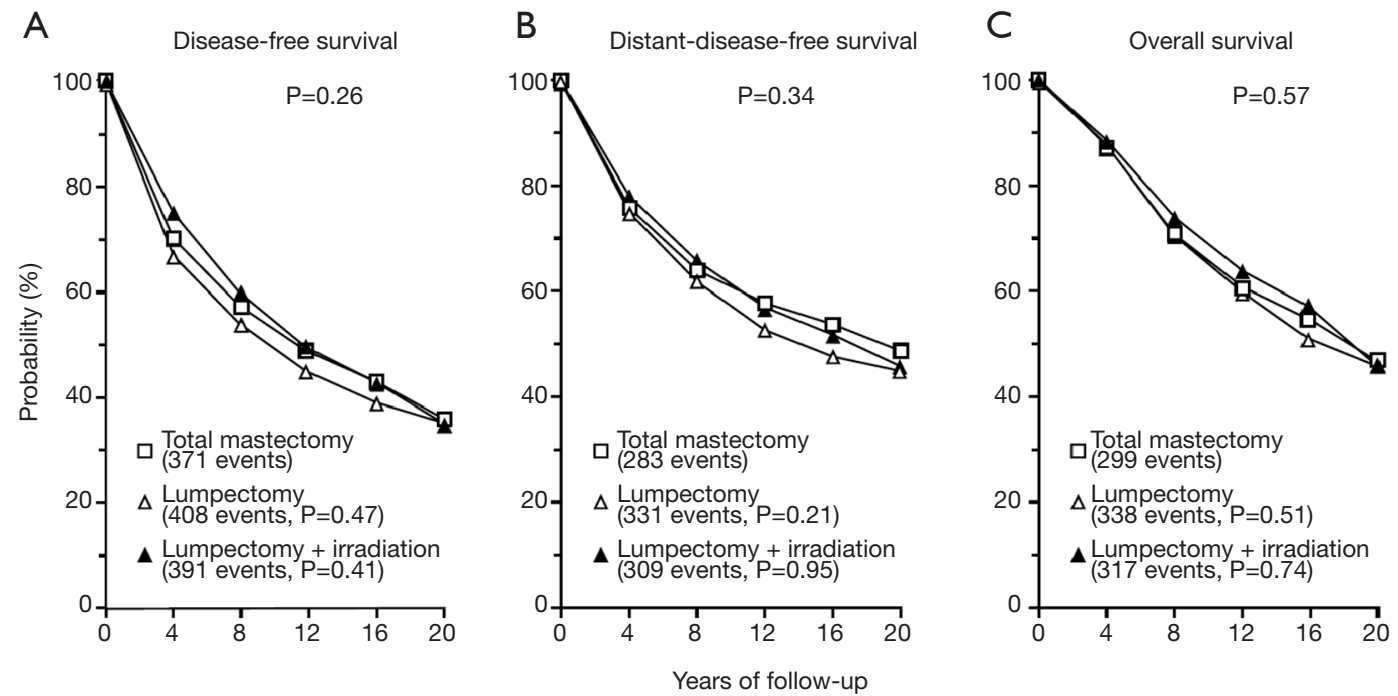

Figure 3 NASABP B-06 results. Disease-free survival (A), distant-disease-free survival (B), and overall survival (C) among 589 women treated with total mastectomy, 634 treated with lumpectomy alone, and 628 treated with lumpectomy plus irradiation. In each panel, the $\mathrm{P}$ value above the curves is for the three-way comparing among the treatment groups; the $\mathrm{P}$ values below the curves are for the two-way comparisons lumpectomy alone or with irradiation and total mastectomy (8). 
Table 1 Veronesi et al. 2002 NEFM 20-year follow up of randomized study comparing Rad mastectomy vs. BCS in early breast cancer (10)

\begin{tabular}{|c|c|c|c|c|c|}
\hline Event & \multicolumn{2}{|c|}{ Radical mastectomy $(\mathrm{N}=349)$} & \multicolumn{2}{|c|}{ Breast-conservation therapy $(\mathrm{N}=352)$} & $P$ value \\
\hline Local recurrence & 8 & 0.17 & 30 & 0.63 & NA \\
\hline Contralateral-breast carcinoma & 34 & 10.2 & 29 & 8.7 & 0.5 \\
\hline Distant metastases & 83 & 24.3 & 82 & 23.3 & 0.8 \\
\hline
\end{tabular}

*, per 100 woman-year of observation. ${ }^{\text {}, ~ c a l c u l a t e d ~ u s i n g ~ G r a y ~ T e s t . ~}$

chemotherapy or endocrine therapy. Collective literature suggests an involved margin rate in BCS is reported to be between $20-40 \%$. These patients require re-excision or completion mastectomy depending upon the remaining breast volume (19). Post BCS, residual tumour burden within the remaining breast is a risk factor for loco-regional recurrence. Holland et al. studied the probability of residual cancer in the breast beyond the reference tumour by painstaking pathological examination of entire mastectomy specimens at radial intervals. These were unifocal tumours that would be considered suitable for BCS (20). The results showed that the probability of further tumour foci was greatest within $2 \mathrm{~cm}$ of the excised tumour margin (29\%) and was higher if there was an extensive intraductal component (59\%). At $4 \mathrm{~cm}$ from the reference tumour the probability of finding cancer remaining in the breast after simulated local excision was $12 \%$ and $32 \%$ if there was an extensive intraduct associated component. Even at $8 \mathrm{~cm}$, the risk of residual disease in the breast was $3 \%$ and $9 \%$. This aligns with the concept of 'Sick lobe' theory and highlights the role for radiotherapy and further excision. However, over the last few decades with better imaging techniques and closer attention to margin assessment the LRR has decreased (6). In attempting to reduce this re-excision rate, multiple strategies have been investigated such as extra cavity shavings with frozen section, intraoperative ultrasound scan (USS), different localisation techniques, e.g., iodine 125 seeds and OBCS. An effective technique for universally negative margins at first lumpectomy is yet to be established. The Holland data provides the historical evidence for why overt attempts at obtaining wider surgical margins, is less important than minimising the residual tumour burden and then applying best whole breast radiotherapy techniques.

We have witnessed a reduction in rates of LRR due to multiple factors other than just achieving negative margins.
Overall the current rate of breast cancer local recurrences is reported to be $1 \%$ per annum (6). The Oxford Overview demonstrates that $75 \%$ of local recurrences occur within 5 years of surgery and confirmed the observation that for every 4 local recurrences prevented by adjuvant radiotherapy, 1 breast cancer death was prevented (21). Local recurrence has been shown to be a risk factor for the development of distant disease and hence optimal local control of breast cancer still remains an essential part of BC management. Adequate local control has been shown to confer a survival benefit at long-term follow-up.

In addition to the time-honoured principles of clear surgical margins and local radiotherapy, the underlying molecular subtype of the primary breast cancer has likely also a major role to play. A recent large meta-analysis of over 12,500 patients showed that patients with luminal subtype compared to triple negative and HER-2 negative breast cancer were less likely to develop LRR in both BCT and mastectomy group (22). This may explain why systemic therapy can have a contributory role in controlling locoregional as well as distant recurrences (23). Effective locoregional control of breast cancer requires a multimodal treatment approach that is personalised to individual patients.

\section{Impact of breast imaging on BCS}

Preoperative imaging is essential for breast conservation surgery planning and localisation. Digital mammography with tomosynthesis has been readily available since 2011. It has overcome some of the limitations of 2D mammography, where lesions can be missed due to tissue-overlap that occurs on planar images. Tomosynthesis is particularly useful in the setting of dense breast tissue (24).

MRI has been shown to more accurately identify the full extent of the invasive and non-invasive disease in multiple studies $(25,26)$. However, the key questions are 


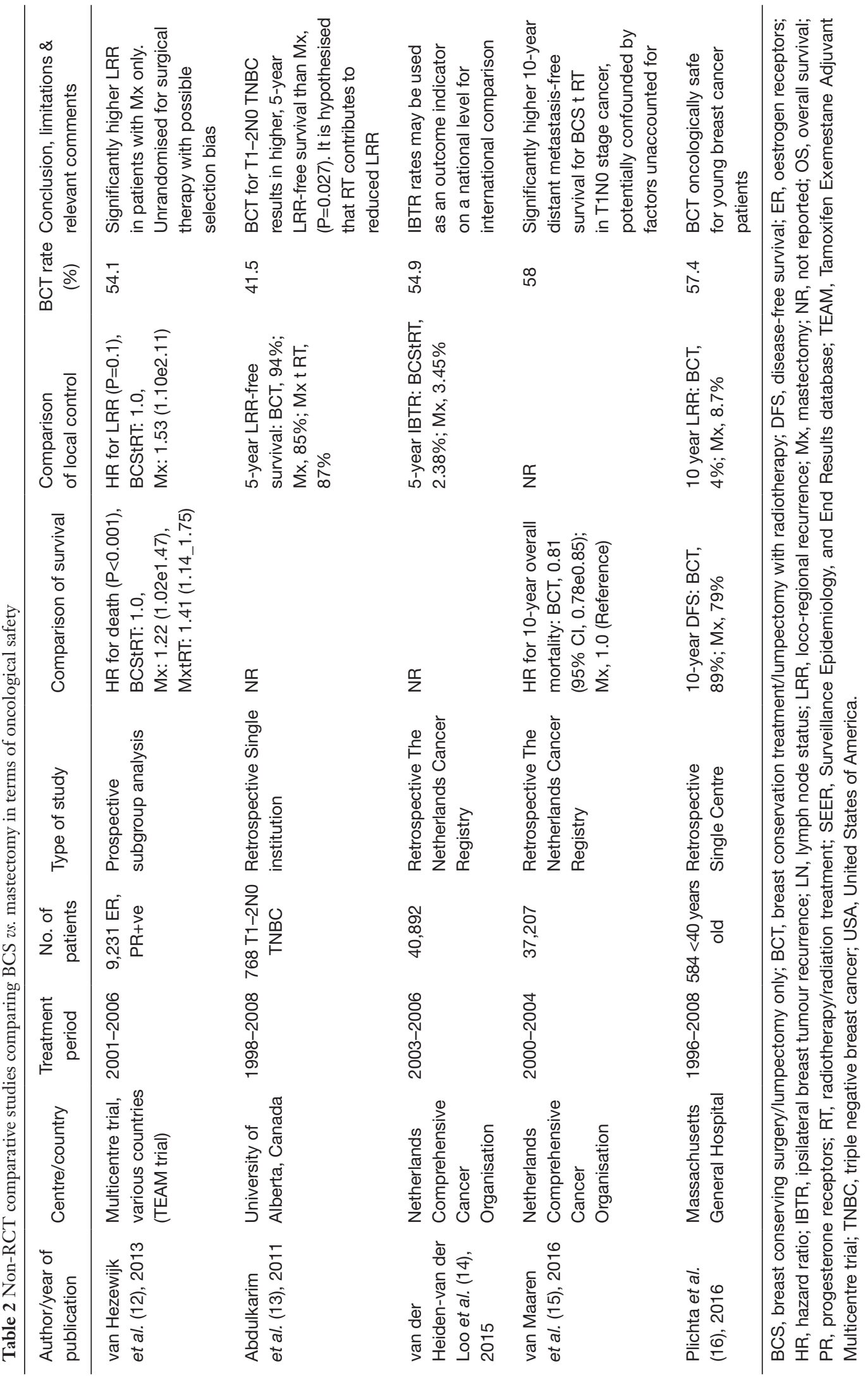


whether MRI in assisting surgical planning for BCS reduces re-excision rates or improves the aesthetic of BCS while maintaining local control. A meta-analysis by Houssami, showed that in women with breast cancer planned for BCS, preoperative MRI can detect additional disease (multifocal and multicentric disease). In $16 \%$ of patients, that leads to more extensive surgery with wider margins or conversion from BCS to mastectomy in $8.1 \%$ (95\% CI, $5.9-11.3 \%$ ) with a positive predictive value of $66.0 \%$ (95\% CI, $52-77 \%$ ) (27). Similarly, another meta-analysis of 12 observational studies also concluded that preoperative MRI, leads to more mastectomies but did not lead to improved surgical treatment or outcomes (27). A prospective RCT from UK (COMICE) trial using preoperative MRI compared to standard imaging found that there was no difference in positive margin or re-excision rates (28). The MONET prospective RCT investigated preoperative MRI use in non-palpable breast cancer and concluded that routine MRI leads surgeons to excise less tissue and therefore higher re-excision rates (34\% with MRI use $\mathrm{n}=74$ vs. $12 \%$ with standard mammogram and USS, $\mathrm{n}=75$ ) (29). Roland Holland in his landmark paper in 1985 clearly showed that the extent of disease is under-estimated by conventional imaging, yet regardless, the application of well-directed surgery to the reference tumour that minimises the amount of potential residual disease, combined with whole breast radiation results in very acceptable rates of local control. Perhaps MRI in many instances is simply demonstrating the findings of such historic studies, and that a minimal amount of residual disease is acceptable when combination therapy as defined in BCT is appropriately applied.

Hence, patients need to be appropriately counselled about the pros and cons of MRI and the potential need for further biopsies. Indeed MRI might potentially lead to change of surgical plan from BCS to mastectomy without necessarily improving surgical outcomes. In our practice, we use MRI in selected situations such as normal mammogram and ultrasound in the presence of confirmed axillary metastasis, discordance between clinical examination findings and conventional imaging and routinely in young high risk women when conventional imaging is normal.

\section{Role of oncoplastic techniques in early and locally advanced breast cancer (LABC)}

The introduction of population based screening for breast cancer has resulted in an increased detection of smaller impalpable breast cancers and hence the rate of BCS has steadily increased over the years. Initially, BCS was deemed suitable for patients with small unifocal cancers of 2 to $4 \mathrm{~cm}$. Patients presenting with larger tumours in relation to breast volume, or tumours with $\mathrm{T} 4$ features such as ulceration or inflammatory features required mastectomy. Oncoplastic Breast Conservation Surgery (OBCS) combines oncological principles of surgery and plastic surgical techniques to excise larger volumes of breast tissue. It increases the scope to obtain clear margins for larger tumours whilst maintaining good cosmesis.

A standard BCS technique (sBCS) has limitations for larger tumours with an increased likelihood of involved margins. Subsequent reoperation to re-excise an involved margin creates a larger cavity, postoperative deformity and poor aesthetic outcome (30). The reported rate of involved margin status when using sBCS techniques is $10-40 \%$ of cases with re-excision rates ranging from $20-60 \%$ of patients (10,30-35). Re-excision leads to further tissue loss and in sBCS technique without tissue re-arrangement, the large empty excisional cavity will scar and retract leading to a deformed breast contour $(36,37)$. In addition to the psychological impact of poor cosmesis, there is increased morbidity, complications and healthcare costs (37). Although the volume of breast tissue excised is the single most important factor influencing cosmetic outcome, there are other factors such as the size and consistency of the breast, re-operation, breast ptosis, tumour location (located inner upper or lower quadrant) and radiation dose which affect cosmetic outcomes (38-42).

OBCS involves excision of tumour tissue with correction of the defect using techniques of varying complexity from simple glandular mobilization to maintain the breast shape to more extensive volume displacement or replacement techniques and reduction mammoplasty. OBCS may also involve symmetrizing procedure on the contralateral breast. The choice of OBCS technique is based on the size and location of tumour, volume, consistency or density and degree of ptosis of the breast. There are numerous reports published describing all the oncoplastic surgical techniques (43-47).

OBCS has been widely accepted into clinical practice, facilitating breast conservation treatment where in the past, the tumour to breast volume ratio would have resulted in mastectomy with or without reconstruction. OBCS technical courses are conducted throughout the world to train General/Plastic Breast surgeons. OBCS skills are an integral part of post-fellowship training in Breast cancer 
surgery in the UK, Europe and Australia.

OBCS provides the ability to perform larger volume excisions for larger tumours (T2 and T3) and obtain clear margins with good aesthetic outcome. Other potential benefits include avoiding the physical and psychological morbidity of additional surgery or the cost of further surgery associated with mastectomy with or without reconstruction. Despite the widespread use of OBCS, there is still a paucity of high quality evidence to support these benefits. Currently, the highest level of evidence we have are based on comparative observational studies (19).

A series of studies showed that OBCS resulted in almost four times the volume of tissue excised compared to sBCS (48-51). As per the recent SSO/ASTRO consensus statement on margins for invasive disease, it is established that a larger margin doesn't result in better LR control when combined with radiotherapy. Hence, a larger margin and subsequent volume excision is not necessary for improved locoregional control. A systematic review of 49 studies and more than 5,000 patients undergoing OBCS reported a positive margin (i.e., tumour at ink margin) in $7.8 \%$ patients, which is lower than reported $15-47 \%$ positive margins rates reported for standard BCS. The weighted average re-excision rate and completion mastectomy rate was $6.0 \%$ and $6.2 \%$ respectively (52). Another large retrospective cohort study $(n=1,177)$ supports these findings of a low positive or close margin rate $5.8 \%$, compared with $8.3 \%$ for sBCS. It did not however report on the subsequent impact of this on surgical management in-terms of re-excision or completion mastectomy (53). The limitations of all these retrospective observational studies include: significant variability in the extent of oncoplastic resection, lack of complete clinical pathological information and adjuvant therapy use.

Current evidence for oncological safety of OBCS is sourced from comparative studies reporting local recurrence rates and survival. Given OBCS is utilised more for larger T2 and T3 tumors (a poor prognostic marker), these patients oncological outcomes such as survival and local recurrence rates should be compared against patients who have had mastectomy as these patents would have otherwise undergone mastectomy instead of BCS (19). There were three retrospective comparative studies that compared OBCS with mastectomy and sBCS with follow up from 3.4 to 7.2 years $(53-55)$.

The largest study from the MD Anderson Cancer centre included 9,861 consecutive patients who underwent OBCS $(n=1,177)$, simple mastectomy $(n=3,263)$, sBCS $(n=3,559)$ and mastectomy with immediate reconstruction $(n=2,608)$ with a follow up period of 3.4 years. The findings showed that although patients undergoing OBCS had more aggressive disease than those treated with sBCS, there was no difference in 3-year OS (95.8\% vs. 96.8\%) and recurrence-free survival (94.6\% vs. 96.1\%) Although, they did not perform a direct comparison with the mastectomy alone group and OBCS, the mastectomy group had the worst outcome of all the groups. There was a lower LRR and OS in the mastectomy with reconstruction group, which was due to the large number of in-situ only disease and stage 0 in this group (53). The limitations of this study are the short follow-up period and the fact the control groups were not matched for clinic-pathological factors.

The largest of these studies by the Italian group De Lorenzi et al., the control groups were matched for age, year of surgery, and tumour size and had a longer follow up period of 7.2 years. Their findings did not show a statistically significant difference in the incidence of local recurrence, distant recurrence, OS and DFS (54,56). These studies provide some evidence for the oncological safety of OBCS in the treatment of suitable breast cancer patients.

Certain types of OBCS can require more extensive operative time than sBCS and a potentially increased complications rate, especially level 2 OBCS techniques. The most recent systematic review mentioned above also explored this question (52). They reported $14.3 \%$ of patients who had OBCS developed complications such as fat necrosis $(3.3 \%)$, skin necrosis $(0.5 \%)$, hematoma $(2.5 \%)$, seroma $(1.0 \%)$, delayed wound healing $(2.2 \%)$, nipple necrosis $(0.4 \%)$ and wound infection $(1.9 \%)$. One third of the patients in this review underwent modified wise pattern for volume displacement surgery, $14.8 \%$ had round block excision and $9.5 \%$ had Latissimus Dorsi volume replacement procedures. The comparative study by MD Anderson's group showed that OBCS had similar hematoma, surgical site infection and lower seroma rate than sBCS (53).

The other concern with OBCS is that it has the potential to delay adjuvant chemotherapy and/or radiotherapy. However, current observational studies do not support this concern for both adjuvant radiotherapy and chemotherapy (51,57-65). Localisation of the tumour bed with small clips at the time of the OBCS helps the radiation oncologist to accurately deliver radiation boost dose to tumour bed (66).

In addition to surgical and oncological outcomes of OBCS, it is important to measure the aesthetic outcomes of OBCS from both surgeon and patients' perspective. There 
Table 3 Key land mark trials in NACT use in breast cancer

\begin{tabular}{|c|c|c|c|c|c|}
\hline Study & $\begin{array}{l}\text { Chemotherapy } \\
\text { regime }\end{array}$ & Study design & Patient (N) & Follow up & Outcomes \\
\hline $\begin{array}{l}\text { NSABP B-18 } \\
{[1997](68)}\end{array}$ & $\begin{array}{l}\text { Doxorubicin; } \\
\text { cyclophosphamide }\end{array}$ & $\begin{array}{l}\text { Randomised, multi-centre } \\
\text { trial; over } 4 \text { cycles }\end{array}$ & $\begin{array}{l}\mathrm{N}^{*}=1,523: \\
\text { pre-op }{ }^{\ddagger}=747, \\
\text { post-op }=759\end{array}$ & $\begin{array}{l}\text { Mean } \\
9.5 \text { years }\end{array}$ & $\begin{array}{l}\text { No significant difference in OS or } \\
\text { DFS; breast tumor size in } 80 \% \text { of } \\
\text { patients; } 37 \% \text { increase in incidence } \\
\text { of pNO } ; \text { t tumour }>50 \mathrm{~mm} \text { had } \\
\text { statistically significant conversion } \\
\text { from mastectomy to BCS }\end{array}$ \\
\hline $\begin{array}{l}\text { EORTC } 10902 \\
{[2001](69)}\end{array}$ & $\begin{array}{l}\text { Fluorouracil; } \\
\text { epirubicin; } \\
\text { cyclophosphamide }\end{array}$ & $\begin{array}{l}\text { Randomised, multi-centre } \\
\text { trial; } 56 \text { months follow up }\end{array}$ & $\begin{array}{l}\mathrm{N}^{\star}=698: \\
\text { pre-op }{ }^{\dagger}=350, \\
\text { post-op }=348\end{array}$ & $\begin{array}{l}\text { Median } \\
56 \text { months }\end{array}$ & $\begin{array}{l}\text { No significant difference in OS or PFS; } \\
23 \% \text { patients downstaged to BCS }\end{array}$ \\
\hline
\end{tabular}

*, population of study; ${ }^{\text {}}$, neoadjuvant chemotherapy cohort; ${ }^{\ddagger}$, adjuvant chemotherapy cohort; ${ }^{*}$, pathologically negative nodes. OS, overall survival; DFS, disease free survival; PFS, progression free survival; BCS, breast conservation surgery.

are a variety of methods to evaluate aesthetic outcomes. Validated and non-validated assessment tools can be given to patients or independent panel based evaluation tools can be used to measure the aesthetics of OBCS. Timing of these evaluations is also important and they should be performed at least 2 years post-operatively and after radiation therapy (67). The significance of good cosmesis is highlighted by the correlation between cosmetic outcome and anxiety and depression score, body image, sexuality and self-esteem. A poor cosmetic outcome of the breast following breast cancer treatment has a high impact on patients' quality of life, being a daily reminder of their previous breast cancer and of their treatment period.

\section{Role of neo-adjuvant chemotherapy in EBC}

The benefits of neoadjuvant chemotherapy (NACT) in breast cancer are two-fold. The ultimate goal of NACT is tumour regression, aiming for a complete pathological response (pCR). NACT also has a role in determining the surgical management of the breast and axilla. Response to NACT may be partial but still achieve a reduction in tumour size allowing for breast conserving surgery (BCS), where formerly a mastectomy may have been the only option. As previously stated, lower excision volume is an independent factor that determines cosmetic outcome in BCS. Another potential benefit of NACT in EBC is down-staging the node positive axilla to potentially reduce the extent of axillary dissection and hence reduce the risk of arm morbidity. The other additional benefit of NACT is early understanding of the tumour response to chemotherapy and hence insight into tumour biology and potential progress of disease. Indications for NACT in breast cancer may include high tumour to breast ratio, multifocal disease and node positive patients. The decision for NACT must take into account patient expectations, particularly when being used to facilitate BCS.

The earliest randomised studies assessing NACT in EBC were undertaken in late 1980s and 1990s. The National Surgical Adjuvant Breast and Bowel Project (NSABP B-18) (68) and European Organization of Research and Treatment of Cancer (EORTC) (69) both established two main conclusions (Table 3):

(I) There is no significant difference in overall survival or DFS in NACT compared to adjuvant chemotherapy;

(II) There is a substantial increase in BCS post NACT compared to adjuvant therapy only (Table 3).

The effect of NACT on excision margins is unclear due to insufficient published good quality evidence. Gerber $\mathrm{et} a \mathrm{l}$. (GeparQuinto trial) reported overall margin involvement in $26.5 \%$ patients in 1,948 patients receiving NACT (70). Assersohn et al. demonstrated a higher rate of involved margins (39.8\% vs. 36.4\%) in patients receiving neoadjuvant chemoendocrine therapy compared to adjuvant only in their randomised controlled trial of 184 patients. However, this did not affect distant recurrence or overall survival (71). Other comparative retrospective studies report a wide variation in positive margins post NACT than adjuvant therapy only $(5-39.8 \%$ in NACT vs. $13.1-46 \%$ without NACT) (72,73). The pathological pattern of response can be concentric or fragmented. The latter may increase the complexity of surgical excision to attain clear margins. Even in the setting of pCR, the objective is to excise the bulk of the initial tumour size to rule out residual disease without 
compromising comesis.

The suitability for BCS is heavily dependent on excision volumes. There is a paucity of strong evidence of volume differences in patients with NACT compared to adjuvant. In a prospective, randomized controlled trial by Boughey et al., significant volume differences were noted in T2 or T3 tumours (113 vs. $\left.213 \mathrm{~cm}^{3}, \mathrm{P}=0.0055\right)$ in standardised patients (74). This was also observed in a study done by Karanlik et al. in 251 patients with excision volumes smaller in NACT group (158.1 vs. $132.2 \mathrm{~cm}^{3}, \mathrm{P}=0.04$ ) (75). However, these studies are small in nature and discordant with evidence from other retrospective studies, the effect of NACT on excision volume remains unclear. Tiezzi et al. reported larger excision volumes post NACT (108 vs. $78 \mathrm{~cm}^{3}, \mathrm{P}=0.002$ ) and no difference seen in either group in a Dutch national pathology database study $\left(50\right.$ vs. $46 \mathrm{~cm}^{3}$, $\mathrm{P}=0.14)(76,77)$. No published data report a subset analyse of preoperative factors such as receptor status or histological variance on excision volumes.

A recent meta-analyses incorporating 4,756 patients from 10 randomised controlled trials illustrated that (78):

(I) More than two-thirds of women allocated to NACT had complete or partial clinical response;

(II) Re-established the positive association of NACT with BCS;

(III) NACT was associated with a higher local recurrence (21.4\% vs. $15.9 \%, \mathrm{RR} 1.37, \mathrm{P}<0.05)$ than adjuvant chemotherapy;

(IV) No difference in distant recurrence or overall survival between NACT and adjuvant chemotherapy.

The study also re-affirmed that poorly differentiated, hormone negative breast cancers are most likely to achieve pCR. In a recent 2018 study undertaken by Asano et al, the presence of tumour-infiltrated lymphocytes illustrates a significantly higher rate of $\mathrm{pCR}$ in triple negative and HER2 positive breast cancer (45.9\% and 50\% respectively). Hormone positive breast cancer has a lower association with pCR with only $26.3 \%$ of patients in this study (79). Previous studies assessing the residual tumour burden scores for different subtypes also showed a higher RCB-0 (complete traces of residual disease) in hormone negative and HER2 positive breast cancer with RCB-III (extensive residual disease) highest in hormone positive and HER2 negative cancer. As pCR is associated with a three-fold increase in overall survival compared to non-pCR in all subtypes of breast cancer (80), the use of NACT in hormone negative and HER 2 positive patients should be strongly considered.

Given the significance of $\mathrm{pCR}$, it is important to preoperatively identify responders to NACT using imaging modality and to confidently exclude residual tumour. The accuracy of MRI assessment to identify residual disease after NACT is high for patients with HER2 positive and hormone negative cancers with less than $0.1 \mathrm{~cm}$ difference in radiological and pathological size in a 2011 study (81). However, as MRI is expensive and not available at all centres particularly in rural areas, the ideal modality needs to be accessible, relatively inexpensive and reliable. In a recent study looking at the value of ultrasound, the overall sensitivity and specificity was $60.8 \%$ and $78.0 \%$ respectively for predicting remission (82). Ultrasound provided the most accurate means of determining residual tumour for triple negative cancers with a negative predictive value of $16.7 \%$.

Furthermore, another study showed radiology was more reliable in predicting response in triple negative cancers in a randomised controlled trial of 188 patients compared to luminal type (83). Therefore, ultrasound and MRI can be obtained in selective patients to predict response to NACT and improve the odds of BCS

Another issue to explore in patients with pCR, is there a role to completely omit surgery or radiotherapy. The omission of surgery post NACT was evaluated in two studies which showed a local recurrence rate (LRR) of 21-23\% in patients treated with radiotherapy only compared to $10-12 \%$ with surgery in a total of 1,930 patients and a majority of T2-3 lesions (84). Therefore, as the recurrence rate is suboptimal in patients with non-operative therapy post NACT, undertaking a core biopsy to assess response may be an option. Currently, there is an observational prospective cohort multicenter trial in Europe (MICRA study) underway to assess the value of core biopsy in patients with radiological and clinical complete response and correlate with their surgical histopathology.

Clearly NACT is beneficial for selected patients. Careful assessment coupled with high quality radiological imaging facilitates more BCS. Further definitive research will help us to define the best choice of imaging modality and with directed core biopsy, allow accurate assessment of response. In some cases, even a non-operative management plan may be suitable.

\section{Role for mastectomy and breast reconstruction still remains}

BCT for EBC is well established and the oncological equivalence to mastectomy is undisputed. Psychological studies suggest BCT has benefits over mastectomy in terms 
of anxiety, body image, sexuality and self-esteem (85). However, paradoxical there has been an increase in mastectomy rates in women with $\mathrm{EBC}$ who are suitable for $\mathrm{BCS}$. This is despite advancements in oncoplastic techniques and the increasing use of NACT to downstage multifocal and large breast cancers to allow the use of BCS (86). The reasons for this trend in mastectomies rates are yet to be fully elucidated.

Although there may be some variations between surgeons in their surgical recommendations (87). Through the process of informed consent most of these individual surgeon preferences are accounted for. The patient's individual preferences, priorities and perceived acceptable risks determine their final decision $(88,89)$. These patients who make an informed decision and exercise their autonomy are likely to be more satisfied and cope with their decision to have mastectomy. Hence, mastectomy should not be viewed as failure to achieve best practice outcomes. Currently, there is a need for more qualitative studies to understand the complex process involved in patients' decisions and measure their satisfaction and empowerment prior to enforcing BCS rate as a quality assurance measures.

\section{Conclusions}

When compared to mastectomy, BCS is not only oncologically safe but also has a positive impact on the aesthetic outcome and psychological well-being of patients with breast cancer. The success of BCS depends on appropriate patient selection. There has been an evolution of developments to facilitate BCS: OBCS surgical technique, more accurate imaging, understanding pathological subtypes and where appropriate use of NACT to downstage the tumour. These are key elements of tailored breast cancer management planning necessary to obtain oncologically safe and aesthetically satisfying outcomes for patients with breast cancer. However, mastectomy rate is no longer an appropriate measure of quality of care even with the increased applicability of BCS. Increasing mastectomy rates in patients who would otherwise be suitable for BCS would be better understood if we take into consideration of hereditary risk, tumour related factors and greater acknowledgement of patient choice. Further research is necessary to understand the factors involved in a patient's decision-making process and satisfaction with their choice of surgery. Also there is need to explore the impact of de-escalation of treatment in patients who have had complete pCR to NACT.

\section{Acknowledgements}

Colleen Niland - Thank you for proof reading and editing.

\section{Footnote}

Conflicts of Interest: The authors have no conflicts of interest to declare.

\section{References}

1. Ozmen V. Paradigm Shift From Halstedian Radical Mastectomy to Personlized Medicine. J Breast Health 2017;13:50-3.

2. Fisher B, Fisher ER. Barrier function of lymph node to tumor cells and erythrocytes. I. Normal nodes. Cancer 1967;20:1907-13.

3. Sakorafas GH, Safioleas M. Breast cancer surgery: an historical narrative. Part II. 18th and 19th centuries. Eur J Cancer Care (Engl) 2010;19:6-29.

4. Tot T. Subgross morphology, the sick lobe hypothesis, and the success of breast conservation. Int $\mathrm{J}$ Breast Cancer 2011;2011:634021.

5. Smart CE, Vargas AC, Lakhani SR. Genetic Alterations in Normal and Malignant Breast Tissue. London: Tot T Breast Cancer Springer, 2010.

6. Riedel F, Hennigs A, Hug S, et al. Is Mastectomy Oncologically Safer than Breast-Conserving Treatment in Early Breast Cancer? Breast Care (Basel) 2017;12:385-90.

7. Gourgou-Bourgade S, Cameron D, Poortmans P, et al. Guidelines for time-to-event end point definitions in breast cancer trials: results of the DATECAN initiative (Definition for the Assessment of Time-to-event Endpoints in CANcer trials)dagger. Ann Oncol 2015;26:873-9.

8. Fisher B, Anderson S, Bryant J, et al. Twenty-year followup of a randomized trial comparing total mastectomy, lumpectomy, and lumpectomy plus irradiation for the treatment of invasive breast cancer. $\mathrm{N}$ Engl J Med 2002;347:1233-41.

9. Litière $S$, Werutsky G, Fentiman IS, et al. Breast conserving therapy versus mastectomy for stage I-II breast cancer: 20 year follow-up of the EORTC 10801 phase 3 randomised trial. Lancet Oncol 2012;13:412-9.

10. Veronesi U, Cascinelli N, Mariani L, et al. Twentyyear follow-up of a randomized study comparing breastconserving surgery with radical mastectomy for early breast cancer. N Engl J Med 2002;347:1227-32.

11. Tan MP, Silva E. Addressing the paradox of increasing 
mastectomy rates in an era of de-escalation of therapy:

Communication strategies. Breast 2018;38:136-43.

12. van Hezewijk M, Bastiaannet E, Putter H, et al.

Effect of local therapy on locoregional recurrence in postmenopausal women with breast cancer in the Tamoxifen Exemestane Adjuvant Multinational (TEAM) trial. Radiother Oncol 2013;108:190-6.

13. Abdulkarim BS, Cuartero J, Hanson J, et al. Increased risk of locoregional recurrence for women with T12N0 triple-negative breast cancer treated with modified radical mastectomy without adjuvant radiation therapy compared with breast-conserving therapy. J Clin Oncol 2011;29:2852-8.

14. van der Heiden-van der Loo M, Siesling S, Wouters MW, et al. The Value of Ipsilateral Breast Tumor Recurrence as a Quality Indicator: Hospital Variation in the Netherlands. Ann Surg Oncol 2015;22 Suppl 3:S522-8.

15. van Maaren MC, de Munck L, de Bock GH, et al. 10 year survival after breast-conserving surgery plus radiotherapy compared with mastectomy in early breast cancer in the Netherlands: a population-based study. Lancet Oncol 2016;17:1158-70.

16. Plichta JK, Rai U, Tang R, et al. Factors Associated with Recurrence Rates and Long-Term Survival in Women Diagnosed with Breast Cancer Ages 40 and Younger. Ann Surg Oncol 2016;23:3212-20.

17. McLaughlin SA. Surgical management of the breast: breast conservation therapy and mastectomy. Surg Clin North Am 2013;93:411-28.

18. Moran MS, Schnitt SJ, Giuliano AE, et al. Society of Surgical Oncology-American Society for Radiation Oncology consensus guideline on margins for breastconserving surgery with whole-breast irradiation in stages I and II invasive breast cancer. Ann Surg Oncol 2014;21:704-16.

19. Campbell EJ, Romics L. Oncological safety and cosmetic outcomes in oncoplastic breast conservation surgery, a review of the best level of evidence literature. Breast Cancer (Dove Med Press) 2017;9:521-30.

20. Holland R, Veling SH, Mravunac M, et al. Histologic multifocality of Tis, T1-2 breast carcinomas. Implications for clinical trials of breast-conserving surgery. Cancer 1985;56:979-90.

21. Early Breast Cancer Trialists' Collaborative Group (EBCTCG), Darby S, McGale P, et al. Effect of radiotherapy after breast-conserving surgery on 10year recurrence and 15-year breast cancer death: metaanalysis of individual patient data for 10,801 women in 17 randomised trials. Lancet 2011;378:1707-16.

22. Lowery AJ, Kell MR, Glynn RW, et al. Locoregional recurrence after breast cancer surgery: a systematic review by receptor phenotype. Breast Cancer Res Treat 2012;133:831-41.

23. Mannino M, Yarnold JR. Local relapse rates are falling after breast conserving surgery and systemic therapy for early breast cancer: can radiotherapy ever be safely withheld? Radiother Oncol 2009;90:14-22.

24. Rafferty EA, Park JM, Philpotts LE, et al. Assessing radiologist performance using combined digital mammography and breast tomosynthesis compared with digital mammography alone: results of a multicenter, multireader trial. Radiology 2013;266:104-13.

25. Berg WA, Gutierrez L, NessAiver MS, et al. Diagnostic accuracy of mammography, clinical examination, US, and MR imaging in preoperative assessment of breast cancer. Radiology 2004;233:830-49.

26. Liberman L, Morris EA, Dershaw DD, et al. MR imaging of the ipsilateral breast in women with percutaneously proven breast cancer. AJR Am J Roentgenol 2003;180:901-10.

27. Houssami N, Hayes DF. Review of preoperative magnetic resonance imaging (MRI) in breast cancer: should MRI be performed on all women with newly diagnosed, early stage breast cancer? CA Cancer J Clin 2009;59:290-302.

28. Turnbull L, Brown S, Harvey I, et al. Comparative effectiveness of MRI in breast cancer (COMICE) trial: a randomised controlled trial. Lancet 2010;375:563-71.

29. Peters NH, van Esser S, van den Bosch MA, et al. Preoperative MRI and surgical management in patients with nonpalpable breast cancer: the MONET randomised controlled trial. Eur J Cancer 2011;47:879-86.

30. Clough KB, Benyahi D, Nos C, et al. Oncoplastic surgery: pushing the limits of breast-conserving surgery. Breast J 2015;21:140-6.

31. Jacobson JA, Danforth DN, Cowan KH, et al. Ten-year results of a comparison of conservation with mastectomy in the treatment of stage I and II breast cancer. N Engl J Med 1995;332:907-11.

32. Fisher B, Anderson S, Redmond CK, et al. Reanalysis and results after 12 years of follow-up in a randomized clinical trial comparing total mastectomy with lumpectomy with or without irradiation in the treatment of breast cancer. $\mathrm{N}$ Engl J Med 1995;333:1456-61.

33. Wanis ML, Wong JA, Rodriguez S, et al. Rate of reexcision after breast-conserving surgery for invasive lobular carcinoma. Am Surg 2013;79:1119-22.

34. Veronesi U, Salvadori B, Luini A, et al. Breast conservation 
is a safe method in patients with small cancer of the breast. Long-term results of three randomised trials on 1,973 patients. Eur J Cancer 1995;31A:1574-9.

35. Biglia N, Ponzone R, Bounous VE, et al. Role of reexcision for positive and close resection margins in patients treated with breast-conserving surgery. Breast 2014;23:870-5.

36. Choi JY, Alderman AK, Newman LA. Aesthetic and reconstruction considerations in oncologic breast surgery. J Am Coll Surg 2006;202:943-52.

37. Al-Ghazal SK, Blamey RW. Cosmetic assessment of breast-conserving surgery for primary breast cancer. Breast 1999;8:162-8.

38. Munshi A, Kakkar S, Bhutani R, et al. Factors influencing cosmetic outcome in breast conservation. Clin Oncol ( $\mathrm{R}$ Coll Radiol) 2009;21:285-93.

39. Taylor ME, Perez CA, Halverson KJ, et al. Factors influencing cosmetic results after conservation therapy for breast cancer. Int J Radiat Oncol Biol Phys 1995;31:753-64.

40. Foersterling E, Golatta M, Hennigs A, et al. Predictors of early poor aesthetic outcome after breast-conserving surgery in patients with breast cancer: initial results of a prospective cohort study at a single institution. J Surg Oncol 2014;110:801-6.

41. Hennigs A, Hartmann B, Rauch G, et al. Long-term objective esthetic outcome after breast-conserving therapy. Breast Cancer Res Treat 2015;153:345-51.

42. Waljee JF, Hu ES, Newman LA, et al. Predictors of breast asymmetry after breast-conserving operation for breast cancer. J Am Coll Surg 2008;206:274-80.

43. Munhoz AM, Montag E, Arruda E, et al. Assessment of immediate conservative breast surgery reconstruction: a classification system of defects revisited and an algorithm for selecting the appropriate technique. Plast Reconstr Surg 2008;121:716-27.

44. Clough KB, Kaufman GJ, Nos C, et al. Improving breast cancer surgery: a classification and quadrant per quadrant atlas for oncoplastic surgery. Ann Surg Oncol 2010;17:1375-91.

45. Kronowitz SJ, Lam C, Terefe W, et al. A multidisciplinary protocol for planned skin-preserving delayed breast reconstruction for patients with locally advanced breast cancer requiring postmastectomy radiation therapy: 3-year follow-up. Plast Reconstr Surg 2011;127:2154-66.

46. Hoffmann J, Wallwiener D. Classifying breast cancer surgery: a novel, complexity-based system for oncological, oncoplastic and reconstructive procedures, and proof of principle by analysis of 1225 operations in 1166 patients.
BMC Cancer 2009;9:108.

47. Berry MG, Fitoussi AD, Curnier A, et al. Oncoplastic breast surgery: a review and systematic approach. J Plast Reconstr Aesthet Surg 2010;63:1233-43.

48. Clough KB, Lewis JS, Couturaud B, et al. Oncoplastic techniques allow extensive resections for breast-conserving therapy of breast carcinomas. Ann Surg 2003;237:26-34.

49. Clough KB, Oden S, Ihrai T, et al. Level 2 oncoplastic surgery for lower inner quadrant breast cancers: the LIQ-V mammoplasty. Ann Surg Oncol 2013;20:3847-54.

50. Fitoussi AD, Berry MG, Fama F, et al. Oncoplastic breast surgery for cancer: analysis of 540 consecutive cases [outcomes article]. Plast Reconstr Surg 2010;125:454-62.

51. Rietjens M, Urban CA, Rey PC, et al. Long-term oncological results of breast conservative treatment with oncoplastic surgery. Breast 2007;16:387-95.

52. De La Cruz L, Blankenship SA, Chatterjee A, et al. Outcomes After Oncoplastic Breast-Conserving Surgery in Breast Cancer Patients: A Systematic Literature Review. Ann Surg Oncol 2016;23:3247-58.

53. Carter SA, Lyons GR, Kuerer HM, et al. Operative and Oncologic Outcomes in 9861 Patients with Operable Breast Cancer: Single-Institution Analysis of Breast Conservation with Oncoplastic Reconstruction. Ann Surg Oncol 2016;23:3190-8.

54. De Lorenzi F, Loschi P, Bagnardi V, et al. Oncoplastic Breast-Conserving Surgery for Tumors Larger than 2 Centimeters: Is it Oncologically Safe? A Matched-Cohort Analysis. Ann Surg Oncol 2016;23:1852-9.

55. Mansell J, Weiler-Mithoff E, Stallard S, et al. Oncoplastic breast conservation surgery is oncologically safe when compared to wide local excision and mastectomy. Breast 2017;32:179-85.

56. De Lorenzi F, Hubner G, Rotmensz N, et al. Oncological results of oncoplastic breast-conserving surgery: Long term follow-up of a large series at a single institution: A matched-cohort analysis. Eur J Surg Oncol 2016;42:71-7.

57. Tenofsky PL, Dowell P, Topalovski T, et al. Surgical, oncologic, and cosmetic differences between oncoplastic and nononcoplastic breast conserving surgery in breast cancer patients. Am J Surg 2014;207:398-402; discussion 402.

58. Thornton BP, Stewart DH, McGrath PC, et al. Breast reduction as an alternative treatment option for early breast cancer in women with macromastia. Ann Plast Surg 2006;56:26-30.

59. Spear SL, Pelletiere CV, Wolfe AJ, et al. Experience with reduction mammaplasty combined with breast 
conservation therapy in the treatment of breast cancer. Plast Reconstr Surg 2003;111:1102-9.

60. Song HM, Styblo TM, Carlson GW, et al. The use of oncoplastic reduction techniques to reconstruct partial mastectomy defects in women with ductal carcinoma in situ. Breast J 2010;16:141-6.

61. Munhoz AM, Montag E, Arruda EG, et al. Critical analysis of reduction mammaplasty techniques in combination with conservative breast surgery for early breast cancer treatment. Plast Reconstr Surg 2006;117:1091-103; discussion 1104-7.

62. McCulley SJ, Macmillan RD. Therapeutic mammaplasty-analysis of 50 consecutive cases. Br J Plast Surg 2005;58:902-7.

63. Kronowitz SJ, Hunt KK, Kuerer HM, et al. Practical guidelines for repair of partial mastectomy defects using the breast reduction technique in patients undergoing breast conservation therapy. Plast Reconstr Surg 2007;120:1755-68.

64. Losken A, Elwood ET, Styblo TM, et al. The role of reduction mammaplasty in reconstructing partial mastectomy defects. Plast Reconstr Surg 2002;109:968-75; discussion 976-7.

65. Losken A, Styblo TM, Carlson GW, et al. Management algorithm and outcome evaluation of partial mastectomy defects treated using reduction or mastopexy techniques. Ann Plast Surg 2007;59:235-42.

66. Schaverien MV, Doughty JC, Stallard S. Quality of information reporting in studies of standard and oncoplastic breast-conserving surgery. Breast 2014;23:104-11.

67. Vrieling C, Collette L, Fourquet A, et al. The influence of patient, tumor and treatment factors on the cosmetic results after breast-conserving therapy in the EORTC 'boost vs. no boost' trial. EORTC Radiotherapy and Breast Cancer Cooperative Groups. Radiother Oncol 2000;55:219-32.

68. Fisher B, Brown A, Mamounas E, et al. Effect of preoperative chemotherapy on local-regional disease in women with operable breast cancer: findings from National Surgical Adjuvant Breast and Bowel Project B-18. J Clin Oncol 1997;15:2483-93.

69. van der Hage JA, van de Velde CJ, Julien JP, et al. Preoperative chemotherapy in primary operable breast cancer: results from the European Organization for Research and Treatment of Cancer trial 10902. J Clin Oncol 2001;19:4224-37.

70. Gerber B, von Minckwitz G, Eidtmann H, et al. Surgical outcome after neoadjuvant chemotherapy and bevacizumab: results from the GeparQuinto study (GBG 44). Ann Surg Oncol 2014;21:2517-24.

71. Assersohn L, Powles TJ, Ashley S, et al. Local relapse in primary breast cancer patients with unexcised positive surgical margins after lumpectomy, radiotherapy and chemoendocrine therapy. Ann Oncol 1999;10:1451-5.

72. Ramos M, Diez JC, Ramos T, et al. Intraoperative ultrasound in conservative surgery for non-palpable breast cancer after neoadjuvant chemotherapy. Int J Surg 2014;12:572-7.

73. Komenaka IK, Hibbard ML, Hsu CH, et al. Preoperative chemotherapy for operable breast cancer improves surgical outcomes in the community hospital setting. Oncologist 2011;16:752-9.

74. Boughey JC, Peintinger F, Meric-Bernstam F, et al. Impact of preoperative versus postoperative chemotherapy on the extent and number of surgical procedures in patients treated in randomized clinical trials for breast cancer. Ann Surg 2006;244:464-70.

75. Karanlik H, Ozgur I, Cabioglu N, et al. Preoperative chemotherapy for T2 breast cancer is associated with improved surgical outcome. Eur J Surg Oncol 2015;41:1226-33.

76. Tiezzi DG, Andrade JM, Marana HR, et al. Breast conserving surgery after neoadjuvant therapy for large primary breast cancer. Eur J Surg Oncol 2008;34:863-7.

77. Volders JH, Haloua MH, Krekel NM, et al. Neoadjuvant chemotherapy in breast-conserving surgery Consequences on margin status and excision volumes: A nationwide pathology study. Eur J Surg Oncol 2016;42:986-93.

78. Early Breast Cancer Trialists' Collaborative Group (EBCTCG). Long-term outcomes for neoadjuvant versus adjuvant chemotherapy in early breast cancer: metaanalysis of individual patient data from ten randomised trials. Lancet Oncol 2018;19:27-39.

79. Asano Y, Kashiwagi S, Goto W, et al. Prediction of Treatment Response to Neoadjuvant Chemotherapy in Breast Cancer by Subtype Using Tumor-infiltrating Lymphocytes. Anticancer Res 2018;38:2311-21.

80. Broglio KR, Quintana M, Foster M, et al. Association of Pathologic Complete Response to Neoadjuvant Therapy in HER2-Positive Breast Cancer With Long-Term Outcomes: A Meta-Analysis. JAMA Oncol 2016;2:751-60.

81. McGuire KP, Toro-Burguete J, Dang H, et al. MRI staging after neoadjuvant chemotherapy for breast cancer: does tumor biology affect accuracy? Ann Surg Oncol 2011;18:3149-54. 
82. Baumgartner A, Tausch C, Hosch S, et al. Ultrasoundbased prediction of pathologic response to neoadjuvant chemotherapy in breast cancer patients. Breast 2018;39:19-23.

83. Kaise H, Shimizu F, Akazawa K, et al. Prediction of pathological response to neoadjuvant chemotherapy in breast cancer patients by imaging. J Surg Res 2018;225:175-80

84. Daveau C, Savignoni A, Abrous-Anane S, et al. Is radiotherapy an option for early breast cancers with complete clinical response after neoadjuvant chemotherapy? Int J Radiat Oncol Biol Phys 2011;79:1452-9.

85. Al-Ghazal SK, Fallowfield L, Blamey RW. Comparison of psychological aspects and patient satisfaction following breast conserving surgery, simple mastectomy and breast reconstruction. Eur J Cancer 2000;36:1938-43.

86. Chang JM, Kosiorek HE, Dueck AC, et al. Trends in mastectomy and reconstruction for breast cancer; a twelve year experience from a tertiary care center. Am J Surg 2016;212:1201-10.

87. Morrow M, Jagsi R, Alderman AK, et al. Surgeon recommendations and receipt of mastectomy for treatment of breast cancer. JAMA 2009;302:1551-6.

88. Katz SJ, Lantz PM, Janz NK, et al. Patient involvement in surgery treatment decisions for breast cancer. J Clin Oncol 2005;23:5526-33.

89. Covelli AM, Baxter NN, Fitch MI, et al. 'Taking control of cancer': understanding women's choice for mastectomy. Ann Surg Oncol 2015;22:383-91.
Cite this article as: Murugappan K, Saboo A, Kuo L, Ung O. Paradigm shift in the local treatment of breast cancer: mastectomy to breast conservation surgery. Gland Surg 2018;7(6):506-519. doi: 10.21037/gs.2018.09.01 
Table S1 Summary of landmark randomized control trials comparing breast conservation surgery (BCS) with Mastectomy (Mx) with respect to oncological safety

\begin{tabular}{|c|c|c|c|c|c|c|c|c|c|c|c|c|c|c|}
\hline \multirow[b]{2}{*}{ Study } & \multirow[b]{2}{*}{ Enrolment } & \multirow[b]{2}{*}{$\begin{array}{l}\text { No. of overall } \\
\text { participants }\end{array}$} & \multirow[b]{2}{*}{$\begin{array}{l}\text { Study } \\
\text { period (year) }\end{array}$} & \multirow[b]{2}{*}{ Randomisation } & \multicolumn{3}{|c|}{ Inclusion criteria } & \multirow[b]{2}{*}{ Interventions } & \multirow[b]{2}{*}{ Standardised } & \multirow[b]{2}{*}{ os } & \multirow[b]{2}{*}{ DFS } & \multirow[b]{2}{*}{ Local recurrence } & \multirow[b]{2}{*}{ DM } & \multirow[b]{2}{*}{ Conclusion } \\
\hline & & & & & $\begin{array}{l}\text { Tumour } \\
(\mathrm{mm})\end{array}$ & Axilla & Age (year) & & & & & & & \\
\hline $\begin{array}{l}\text { NSABP B-06 } \\
\text { (8), N Engl J } \\
\text { Med, } 2002\end{array}$ & 1976-1984 & 1,211 & 20 & $\begin{array}{l}\mathrm{Mx}=589 \\
\mathrm{BCS} \text { alone }=634 \\
\mathrm{BCS}+\mathrm{RTX}=628\end{array}$ & $<40$ & No, N1 & $\begin{array}{l}\text { No age } \\
\text { limit }\end{array}$ & $\begin{array}{l}\text { Total } M x+A x \\
\text { vs. } B C S+A x v s . \\
B C S+A x+R T x \\
\text { no boost }\end{array}$ & Yes & $\begin{array}{l}\text { Hazard ratio: } \\
\text { BCS vs. Mx }=1.05 \\
(P>0.05), B C S+R T x \\
\text { vs. BCS alone } 0.97 \\
(P>0.05)\end{array}$ & $\begin{array}{l}\text { Mx 36\%, } \\
\text { BCS. 35\%, } \\
\text { BCS + RTx } \\
35 \%\end{array}$ & $\begin{array}{l}\mathrm{Mx}=10.2 \% \\
\mathrm{BCS}=8.85 \% \\
\mathrm{BCS}+\mathrm{RTx} \\
=2.27 \%(\mathrm{P}<0.05)\end{array}$ & $\begin{array}{l}\mathrm{Mx}=22.4 \%, \mathrm{BCS} \\
24.9 \%, \mathrm{BCS}+\mathrm{RT} x \\
26 \%(\mathrm{P}<0.05)\end{array}$ & $\begin{array}{l}\text { Recurrence was higher in BCS without } \\
\text { RTx compared to with RTx ( } 39.2 \% \text { vs. } \\
14.3 \% \text {. } P<0.001) \text {. There is no difference } \\
\text { in OS, DFS and DM between the three } \\
\text { groups }\end{array}$ \\
\hline $\begin{array}{l}\text { National } \\
\text { Cancer } \\
\text { Institute (31), } \\
\text { N Engl J Med, } \\
1995\end{array}$ & 1979-1987 & 237 & 10.1 & $\begin{array}{l}\mathrm{BCS}=121, \\
\mathrm{MRM}=116\end{array}$ & $<50$ & No, N1 & $\begin{array}{l}\text { No age } \\
\text { limit }\end{array}$ & $\begin{array}{l}\text { MRM + Ax vs. BCS } \\
+ \text { Ax + RTx, beast } \\
\text { reconstruction was } \\
\text { completed in } 59 \% \\
\text { patients in MRM } \\
\text { group }\end{array}$ & s & $\begin{array}{l}\text { MRM (75\%) vs. } \\
\text { BCS (77\%); P>0.05 }\end{array}$ & $\begin{array}{l}\text { MRM (69\%) } \\
\text { vs. BCT } \\
\text { (72\%); } \\
\text { P>0.05 }\end{array}$ & $\begin{array}{l}\text { MRM }(10 \%) \\
\text { vs. BCS (5\%); } \\
\text { P>0.05 }\end{array}$ & $\begin{array}{l}\text { MRM }(19.8 \%) \\
\text { vs. BCS (22.3\%); } \\
\text { P>0.05 }\end{array}$ & $\begin{array}{l}\text { No significant difference in metastatic } \\
\text { disease or overall survival between BCS } \\
\text { and MRM at the 10-year mark }\end{array}$ \\
\hline $\begin{array}{l}\text { EORTC (9), } \\
\text { Lancet Oncol, } \\
2012\end{array}$ & $1980-1986$ & 868 & 22.1 & $\begin{array}{l}\mathrm{BCS}=448, \mathrm{MRM} \\
=440\end{array}$ & $<50$ & No & $<70$ & $\begin{array}{l}\text { MRM vs. BCS + } \\
\text { Ax + RTx } 25 \text { Gy }\end{array}$ & Yes & $\begin{array}{l}\text { MRM }(44.5 \%) \text { and } \\
\text { BCS }(39.1), P>0.05\end{array}$ & Not assessed & Not assessed & $\begin{array}{l}\text { MRM }(42 \% ; 175) \\
\text { vs. BCS }(46 \% ; 207)\end{array}$ & $\begin{array}{l}\text { No significant difference in metastatic } \\
\text { disease or overall survival between BCS } \\
\text { and MRM }\end{array}$ \\
\hline $\begin{array}{l}\text { Danish Breast } \\
\text { Cancer Group } \\
\text { (90), DBCG- } \\
\text { 82TM, } 2008\end{array}$ & 1983-1989 & 793 & 19.6 & $\begin{array}{l}\mathrm{BCS}=367, \mathrm{MRM} \\
=364\end{array}$ & $\begin{array}{l}\text { Any } \\
\text { size }\end{array}$ & $\begin{array}{c}\text { Not } \\
\text { specified }\end{array}$ & $<70$ & $\begin{array}{l}\text { MRM vs. BCS + } \\
\text { Ax + RTx }\end{array}$ & Yes & $\begin{array}{l}\text { MRM }(50.6 \%) \\
\text { vs. BCS (57.8\%); } \\
\text { P>0.05 }\end{array}$ & $\begin{array}{l}\text { MRM }(61.1 \%) \\
\text { vs. BCS } \\
(59.5 \%) \\
\text { P>0.05 }\end{array}$ & $\begin{array}{l}\text { MRM }(21 \%) \\
\text { vs. BCS (13\%); } \\
\text { P>0.05 }\end{array}$ & $\begin{array}{l}\text { MRM (55\%) vs. } \\
\text { BCS (67\%); P>0.05 }\end{array}$ & $\begin{array}{l}\text { New primary breast cancers were } \\
\text { significantly associated with BCS while } \\
\text { true recurrences associated with MRM } \\
(\mathrm{P}<0.001) \text {; no significant difference } \\
\text { in treatment groups with relation to } \\
\text { recurrence, RFS and OS }\end{array}$ \\
\hline $\begin{array}{l}\text { Milan Study } \\
\text { (10), N Engl J } \\
\text { Med, } 2002\end{array}$ & 1973-1980 & 701 & 20 & $\begin{array}{l}\mathrm{BCS}=352, \mathrm{MRM} \\
=349\end{array}$ & $<20$ & $\begin{array}{l}\text { Clinically } \\
\qquad \mathrm{N}\end{array}$ & $<70$ & $\begin{array}{l}\text { Halsted Mx vs. } \\
\text { BCS + Ax + RTx }\end{array}$ & Yes & $\begin{array}{l}\text { Halsted Mx }(58.8 \%) \\
\text { and BCS }(58.3 \%) \\
\mathrm{P}>0.05\end{array}$ & Not assessed & $\begin{array}{l}B C S=8.8 \% \\
\text { Halsted } \\
M x=2.3 \% \\
(P<0.001)\end{array}$ & $\begin{array}{l}\text { Halsted Mx } \\
(24.3 \%) \text { vs. BCS } \\
(23.3 \%) ; P>0.05\end{array}$ & $\begin{array}{l}\text { No significant difference in overall } \\
\text { survival between BCS and MRM. Even } \\
\text { though local recurrence was higher } \\
\text { in BCS, the OS supports the basis of } \\
\text { distant metastatic disease rather than } \\
\text { local }\end{array}$ \\
\hline $\begin{array}{l}\text { Gustave } \\
\text { Roussy (91), } \\
\text { Radiother } \\
\text { Oncol, } 1989\end{array}$ & $1972-1979$ & 179 & 10 & $\begin{array}{l}\mathrm{BCS}=88, \\
\mathrm{MRM}=91\end{array}$ & $<20$ & No, N1 & $<70$ & $\begin{array}{l}\mathrm{MRM}+\mathrm{Az} \text { vs. } \\
\mathrm{BCS}+\mathrm{Ax}+\mathrm{RT} x\end{array}$ & Yes & $\begin{array}{l}\text { MRM }(80 \%), \text { BCS } \\
(79 \%), P>0.05\end{array}$ & $\begin{array}{l}\text { MRM (58\%), } \\
\text { BCS (66\%), } \\
\text { P>0.05 }\end{array}$ & $\begin{array}{l}\text { MRM (10\%), } \\
\text { BCS (5\%), } \\
\text { P>0.05 }\end{array}$ & $\begin{array}{l}\text { MRM (27\%), BCS } \\
(26 \%) P>0.05\end{array}$ & $\begin{array}{l}\text { There is no difference in OS, local } \\
\text { recurrence or distant metastases } \\
\text { between BCS and MRM }\end{array}$ \\
\hline
\end{tabular}

MRM, modified radical mastectomy; RTx, radiotherapy; OS, overall survival; DFS, disease free survival; RFS, recurrence free survival; DM, distant metastases.

\section{References}

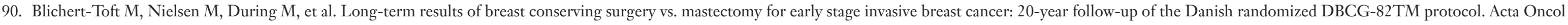
2008;47:672-81.

91. Sarrazin D, Le MG, Arriagada R, et al. Ten-year results of a randomized trial comparing a conservative treatment to mastectomy in early breast cancer. Radiother Oncol 1989;14:177-84. 